\title{
Ortodoxia da criatividade: experiência com artistas em Salvador
}

\author{
Orthodoxy of creativity: experience with artists in Salvador
}

\begin{abstract}
Jefferson Dantas ${ }^{\mathrm{a}}$ (
Resumo O objetivo deste trabalho é compreender a concessão do título de "cidade da música” para Salvador pela Unesco e possíveis redefinições na vida e no trabalho de artistas locais. Indaga-se: como equilibrar a promoção internacional, o desenvolvimento da economia local e a participação dos artistas? A pesquisa informa que a prefeitura municipal ainda está com dificuldades práticas para tornar Salvador a cidade da música proposta por sua candidatura e propaganda iniciais. Isto é perceptível, pois não existe um alinhamento entre discursos e práticas no tocante aos direitos dos artistas, falta uma política cultural clara, há baixo investimento e manutenção precária de espaços de socialização artística. Chegou-se a essa conclusão depois da análise de legislações, relatórios de gestão e entrevistas com artistas.
\end{abstract}

Palavras-chave Artista. Cidade criativa. Experiência. Salvador.

Abstract the objective is to understand the granting of the title of city of music to Salvador by Unesco and possible redefinitions in the life and work of local artists. I wonder: how to balance international promotion, local economic development and the participation of artists? The research reports that the city hall is still having practical difficulties in making Salvador the city of music proposed by its initial candidacy and propaganda. This is noticeable because there is no alignment between discourses and practices regarding artists' rights, lack of a clear cultural policy, low investment and poor maintenance of spaces for artistic socialization. This conclusion was reached after analyzing legislation, management reports and interviews with artists.

Keywords Artist. Creative city. Experience. Salvador.

\section{CONSIDERAÇÕES INICIAIS}

Este texto nasceu a partir de contato com artistas na cidade de Salvador. Estava inicialmente interessado nas condições de trabalho e vida de atores de teatro, contudo na dinâmica do campo, e, principalmente, no convívio com artistas ouvi

a Doutor em Ciências Sociais pela Unicamp. Estuda as artes a partir da categoria trabalho, atento ainda aos marcadores sociais da diferença. 
uma série de alegações conflitantes a respeito da "cidade criativa”. De um lado, um discurso triunfante oriundo, sobretudo, de gestores, do outro uma visão crítica e incrédula vinda de artistas e agremiações culturais.

Neste sentido, examinei textos da Organização das Nações Unidas para a Educação, a Ciência e a Cultura - Unesco, discursos de atores governamentais, a exemplo do prefeito da cidade e duas entrevistas com artistas locais, que falaram de suas vivências, das dificuldades com a burocracia e da necessidade de melhores condições de trabalho. A interpretação conjugou sociologicamente os temas do trabalho, da arte e da cidade.

A pesquisa mostrou que a prefeitura municipal ainda tem dificuldades práticas para tornar Salvador a cidade da música proposta por sua candidatura e propaganda iniciais. Isto é perceptível em razão da falta de direitos dos artistas, de uma política cultural clara, do baixo investimento e da manutenção precária de espaços de socialização artística.

ECONOMIA, CRIATIVIDADE E CIDADE

Ser artista

Na cidade

É comer um fiapo

É vestir um farrapo

É ficar à vontade

É vagar pela noite

É ser um vaga-lume

É catar uma guimba

É tomar uma pinga

É pintar um tapume

É não ter documento

Até que o rapa te pega

Te dobra, te amassa

E te joga lá dentro

(Chico Buarque, A Cidade dos Artistas, 1981)

A letra de Chico Buarque é esclarecedora do processo que tem embaralhado as políticas públicas urbanas com as culturais - refiro-me mais precisamente 
ao título de cidade criativa. Vejamos a definição e o objetivo da cidade criativa, segundo a Unesco:

The UNESCO Creative Cities Network (UCCN) was created in 2004 to promote cooperation with and among cities that have identified creativity as a strategic factor for sustainable urban development. The 116 cities which currently make up this network work together towards a common objective: placing creativity and cultural industries at the heart of their development plans at the local level and cooperating actively at the international level ${ }^{1}$.

Não tomo a economia criativa como uma categoria de análise, mas um termo êmico, ou seja, conceitos e valores mobilizados, principalmente, pelos agentes hegemônicos da cadeia produtiva da cultura, o mercado, mecanismos multilaterais e o Estado. Mobilizações que, com frequência, se referendam nas experiências relacionadas aos governos da Austrália e do Reino Unido, que se destacaram na década de 1990 (Hartley, 2005; Howkins, 2001; Reis, 2011; Seldin, 2015; Thorsby, 2001).

A cidade criativa surge como uma expressão da reorganização da produção capitalista, pressupondo o desenvolvimento na área cultural, prometendo melhorias na vida e no trabalho dos indivíduos, amparada na "fabulação de senso comum econômico, segundo o qual o crescimento enquanto tal faz chover empregos" (ARANTES, 2000, p.27). As elites econômicas têm deslocado a ênfase na industrialização para o paradigma informacional, num processo que vem assediando as elites políticas locais a acatarem tais tendências. Conforme Isar,

A chave para esse paradigma é o argumento de que, enquanto os setores que impulsionaram a revolução urbana do século XIX basearam-se, em grande parte, no uso de matéria-prima, hoje a criatividade baseia-se no conhecimento e nas habilidades; por exemplo, a capacidade de gerar novo conhecimento a partir do conhecimento existente, a capacidade de gerar novas ideias que podem desencadear inovação e suas aplicações concretas. A criatividade ontológica intrínseca das artes tem sido promovida como um caminho privilegiado em direção a

1 A Rede das Cidades Criativas da UNESCO (UCCN) foi criada em 2004 para promover a cooperação entre as cidades que identificaram a criatividade como fator estratégico para o desenvolvimento urbano sustentável. As 116 cidades que, atualmente, compõem esta rede trabalham em conjunto para um objetivo comum: colocar a criatividade e as indústrias culturais no centro de seus planos de desenvolvimento a nível local e cooperar ativamente a nível internacional. Tradução livre feita pelo autor do texto. Disponível em: http://en.unesco.org/creative-cities/ content/about-us. Acesso em: 13 jul. 2019. 
"uma cultura de inovação e criatividade" em uma variedade de domínios (IsAR, 2008, p.81).

Rubim, Vieira e Rubim (2005) localizam, espacial e temporalmente, a origem dessas transmutações:

Não por acaso, a discussão sobre a diversidade cultural tornou-se vital hoje, demandando inclusive a grande reunião da UNESCO, realizada em outubro de 2005, a qual discutiu e aprovou uma convenção internacional sobre diversidade cultural, essencial para a vida cultural no mundo e para a preservação e desenvolvimento de sua maior riqueza: a diversidade cultural, tão fundamental quanto a biodiversidade para o futuro do planeta e da humanidade (RuBIm; VieIRA;RUbim, 2005, p. 6).

Um texto fundamental neste processo é International Flows of Cultural Goods and Services (1994-2003) ${ }^{2}$, lançado em 2005, pela Organização das Nações Unidas para Educação, Ciência e Cultura-UNESCO. Este texto reúne as atividades de bens e serviços culturais que devem ser explorados economicamente em quatro grandes grupos que abrangem catorze segmentos, que envolvem desde as heranças patrimoniais, livros, materiais impressos, mídias digitais, jogos, eletrônicos, royalties e serviços especializados na área cultural.

A força dos bens e serviços culturais foi intensificada pelo relatório de Economia Criativa publicado pelo Programa das Nações Unidas para o Desenvolvimento-PNUD e pela UNESCO, em 2013, apontando para o crescimento do setor criativo, avaliando a geração de renda, a criação de empregos e os ganhos com exportação. Segundo este relatório, o comércio global de bens e serviços criativos mais que dobrou entre 2002 e 2011, atingindo US\$ 624 bilhões em 2011, refletindo cerca de $8,8 \%$ de crescimento ano a ano.

O Brasil está imerso nesta tendência, sobretudo, depois da criação da Secretaria de Economia Criativa do Ministério da Cultura, em 2011. A secretaria foi fundada com a missão de aproximar as pastas da cultura e economia por meio do trabalho. Segundo a Federação das Indústrias do Estado do Rio de Janeiro-FIRJAN, a economia criativa corresponde a $2,64 \%$ do produto interno bruto brasileiro, movimentando cerca de $\mathrm{R} \$ 155,6$ bilhões de reais.

2 Para saber mais consultar: http://unesdoc.unesco.org/images/o014/o01428/142812e.pdf. Acesso em: 11 out. 2018. 
Essa nova economia surge ainda em momento oportuno, visto que vivenciamos uma "época de cuidados redobrados com o planeta, tal atividade não está assentada nos recursos finitos e cada vez mais escassos da natureza" (ARAGÃo;BolAÑo; LOPES, 2016, p.12). Mais um fator mobilizado pelos paladinos da Economia criativa, tendo a concordar com Ursula Huws (2011), no sentido de que se criou uma ortodoxia.

A socióloga inglesa Ursula Huws aponta que:

Uma ortodoxia que toma como certo que o "conhecimento" é a única fonte de valor, que o trabalho é uma eventualidade e não é localizável, que a globalização é um processo inexorável e inevitável e que, por consequência, a resistência é vã e qualquer reivindicação advinda de um corpo físico aqui-e-agora está irremediavelmente fora de moda. As implicações deste "senso comum" emergente são imensas, pois capaz de moldar assuntos tão diversos quanto impostos, legislação trabalhista, níveis de gastos com previdência, direitos de privacidade, e política ambiental. São noções que servem para legitimar uma nova agenda política e estabelecer o cenário para uma nova fase da acumulação de capital (Huws, 2011, p. 26).

Huws (2011), Harvey (1996, 2003, 2005) e Yúdice (2006) mostram o processo de complexificação no qual estão envoltos os bens e serviços criativos, evidenciando não só a acumulação, mas também a administração de conflitos da relação capital/ trabalho e as disputas políticas pelo sentido da cultura e da criatividade. Essa disputa, objetivamente, significa:

A subordinação da criatividade à inovação e à lógica dos direitos de propriedade intelectual implica não somente sua circunscrição a determinados arranjos institucionais, facilitadores dos processos de inovação, quanto seu direcionamento às demandas mercadológicas [...] o deslocamento de uma prática social e coletiva - a cultura - para a esfera das capacidades individuais revela-se como o outro nome do propalado capital humano - as habilidades, as capacidades e as destrezas inatas ou adquiridas do ser humano que possuam valor econômico, segundo os economistas da Escola de Chicago (AragÃo; Bolaño; LoPes, 2016, p. 15).

A face famosa da teoria do capital humano é o empreendedorismo (EHRENBERG, 2010) difundido pelo Serviço Brasileiro de Apoio às Micro e Pequenas Empresas (SEBRAE) desde os anos 1990, agora regulamentado e incentivado pela Lei Comple- 
mentar $\mathrm{n}^{0}$ 128, de 19 de dezembro de 20083 . A tarefa do empreendedorismo, neste contexto, é harmonizar a situação de amplo desemprego, empurrando a responsabilidade pela empregabilidade aos próprios indivíduos.

Os autônomos representam $73,2 \%$ do total de trabalhadores do setor cultural, segundo a Pesquisa Nacional por Amostra de Domicílio - PNAD/IBGE, do último trimestre de 2019, caracterizando a informalidade presente no setor ${ }^{4}$. Já o relatório do Observatório de Economia Criativa da Bahia - OBEC/BA, lançado em 8/5/2020, aponta para a renda destes trabalhadores $-67 \%$ dos profissionais criativos recebem até três salários-mínimos ${ }^{5}$. Desse modo, os artistas vivem num regime de flexibilidade profundo, trabalhando intermitentemente, conciliando diferentes projetos.

Essas dificuldades e desigualdades foram expostas pela pandemia do novo coronavírus. A classe artística teve que recorrer ao legislativo federal para angariar recursos financeiros e conquistou a Lei Aldir Blanc ${ }^{6}$, atenuando a situação que está longe de ser resolvida. Dito isto, passemos à análise da concessão do título à capital baiana, avaliando as ações dos gestores municipais e como essa novidade tem sido recebida entre setores agremiados e independentes da classe artística soteropolitana.

\section{SALVADOR "CIDADE DA MÚSICA": UMA RECEITA PARA CIDADES PÓS-INDUSTRIAIS}

A conciliação entre beleza natural e riqueza artístico-cultural, essa foi a fórmula desenvolvida como trampolim para o desenvolvimento em resposta à fraca/baixa industrialização em Salvador, apostando no turismo como solução para essa ausência. A atividade está baseada no envolvimento de indivíduos ou grupos de pessoas que saem do seu local de residência em busca de lazer, descanso e cultura, gerando múltiplas relações, cuja importância se dá social, econômica e culturalmente. O turismo nas cidades é fruto de planejamento, conforme salienta Sanchez:

Os planos estratégicos propõem atuações integradas a longo prazo, dirigidas à execução de grandes projetos que combinam objetivos de crescimento econômico e desenvolvimento urbano, com um sistema de tomada de decisões que

3 Disponível em:http://www.planalto.gov.br/ccivil_o3/leis/lcp/lcp128.htm. Acesso em: 26 fev. 2020.

4 Para saber mais: https://www.ibge.gov.br/estatisticas/sociais/populacao/9171-pesquisa-nacional-por-amostra-de-domicilios-continua-mensal.html?edicao=27233\&t=destaques. Acesso em: 10 mai. 2020.

5 Ver o terceiro boletim do OBEC/BA, onde 423 profissionais informaram a renda mensal, entre 27 de março a 04 de maio de 2020.

6 Lei $n^{0}$ 14.017, de 29 de junho de 2020, que concedeu auxílio financeiro ao setor cultural. 
comporta riscos, com a identificação de cursos de ação específica, formulação de indicadores de seguimento e envolvimento de agentes sociais e econômicos ao longo do processo (SANCHEZ, 1999, p.115).

Identificam-se estratégias turísticas de city marketing, levadas a cabo por agentes do mercado e políticos locais na promessa de geração de trabalho e renda para a população na articulação do binômio turismo e desenvolvimento, transpondo o modelo estratégico do mundo empresarial para o universo urbano. Nessa toada, a cidade aos poucos vai deixando de ser pública, republicana e aberta, e passa a ser mais fechada, exclusiva e privada, em razão do foco na atração de turista, que paga para ver/sentir a cidade, pondo para escanteio os direitos dos cidadãos residentes.

Do ponto de vista econômico e cultural, Salvador é a maior metrópole da região Nordeste. Sem condições de disputar com São Paulo e Rio de Janeiro pelo título de principal entrada do país, a capital baiana busca se consolidar enquanto terceiro portão de entrada no Brasil, mas, sobretudo, ambiciona não perder o status de importante destino no Norte e Nordeste do país. Assim, vem adotando propostas como a ostentação do título de cidade da música da Unesco.

Na Bahia, o PIB criativo varia entre 1,o e 1,2 \%, ou seja, cerca de 1,5 bilhão de reais (FIRJAN, 2016). Estima-se que o setor de serviços representa 78,2\% da composição econômica de Salvador. Parte generosa dessa riqueza é oriunda do turismo e do entretenimento, que na capital baiana se encontram imbricados, e, por conseguinte, impulsionam o comércio, transporte e restaurantes, entre outros serviços (FERreIrA, 2017). Por isso, nos últimos anos, o governo do Estado da Bahia e a Prefeitura da cidade têm investido em infraestrutura no sentido de abarcar eventos de grande porte, a exemplo dos jogos da Copa do Mundo, Campus Party $e$ shows de artistas como Paul McCartney e Roger Waters.

Salvador tem sido alvo das políticas culturais e patrimoniais da UNESCO desde 1985, quando o centro histórico da cidade foi reconhecido Patrimônio Mundial, devido ao importante exemplar de conjunto arquitetônico ultramarino português ${ }^{7}$. Entre 2015 e 2016 conquistou o título de cidade da música ${ }^{8}$. Sobre isso, disse o então prefeito Antônio Carlos Magalhães Neto:

7 Disponível em: http://portal.iphan.gov.br/pagina/detalhes/35/. Acesso em: 17 mar. 21.

8 São sete os ramos das cidades criativas: Artesanato e artes folclóricas, Design, Cinema, Gastronomia, Literatura, Artes midiáticas e Música. 
Para ser reconhecida como cidade da música, Salvador nem precisaria desse título, porque basta ver a produção dos artistas maravilhosos que temos e que fazem essa cidade diferente de todas as outras. Esse reconhecimento, claro, projeta ainda mais aquilo que é produzido em nossa cidade. A capital baiana é marcada pela diversidade cultural e multiplicidade de gêneros que se projeta para o Brasil e para o mundo. Salvador tem na música uma das mais fortes indústrias de produção econômica, inclusão social e geração de emprego e renda. Esse título vai render muitos frutos no interesse de pessoas que são apaixonadas pela música a conhecerem ainda mais de perto a produção da nossa cidade ${ }^{9}$

Otília Arantes (2000) evidencia que as prefeituras municipais ganharam ares de agências publicitárias, patrocinando e divulgando manifestações de caráter cultural que na visão dos grupos dirigentes merecem relevo, salientando aspectos da cultura para entrar na geopolítica global das cidades turísticas, elaborando uma memória, narrativa e tradição.

Com isso, os grupos dirigentes almejam lucros de natureza política para sua reprodução social, bem como lucros financeiros para setores já privilegiados. Desse modo, a confluência entre políticas urbanas e culturais incorre num processo de espetacularização e mercantilização que fabula a imagem da cidade, prevendo a consolidação de um padrão internacional para o turismo que despreza os cidadãos locais.

Na contramão, os músicos baianos estão apontando as contradições deste projeto, cobrando os direitos autorais sobre eventos musicais organizados pelo município. Nesse sentido, o Escritório Central de Arrecadação e Distribuição ECAD, junto às agremiações que o constituem ${ }^{10}$, protocolou uma carta junto à Unesco sugerindo que o título fosse revisado ou ainda cancelado em razão da dívida.

[...] a mesma prefeitura que usa o título de Cidade da Música como chamariz para investimentos não reconhece o direito dos compositores e não paga direitos autorais pelas músicas que utiliza nos eventos que promove. Na prática, esta

9 Disponível em: http://g1.globo.com/bahia/noticia/2016/o6/unesco-reconhece-oficialmente-salvador-como-cidade-da-musica.html. Acesso em: 24 fev. 2021.

10 ABRAC-Associação Brasileira de Autores, Compositores, Intérpretes e Músicos, ABRAMUS - Associação Brasileira de Música e Artes, AMAR- Associação de Músicos, Arranjadores e Regentes, ASSIM - Associação de Intérpretes e Músicos, SADEMBRA- Sociedade Administradora de Direitos de Execução Musical do Brasil, SBACEM- Sociedade Brasileira de Autores, Compositores e Escritores de Música, SICAM- Sociedade Independente de Compositores e Autores Musicais, SOCINPRO- Sociedade Brasileira de Administração e Proteção de Direitos Intelectuais e UBC- União Brasileira de Compositores. 
inadimplência significa que cada compositor de todas as músicas que animam as festas de Salvador não recebe, há anos, absolutamente nada pelo uso público de suas canções. A prefeitura não reconhece o trabalho do compositor como algo digno de ser remunerado - apesar de promover dezenas de eventos cujo atrativo principal é justamente a música. É contraditória a situação da cidade que se notabiliza por suas canções, mas não permite que os artistas possam viver da sua própria criação musical. Salvador, sede de um dos mais famosos carnavais de todo o mundo, teve de presenciar, neste ano, a manifestação de dezenas de artistas que criticaram a inadimplência da prefeitura, representada por uma dívida milionária de direitos autorais devidos por shows e eventos como os de carnaval e festa junina, entre outros (CARTA Do ECAD A UnESCO BRASIL, 2018).

O título não foi cancelado. Ao contrário, foi renovado em 2020. Mas essa é a primeira vez que grupos locais brasileiros buscam anulação de um título supranacional da área cultural. No período da candidatura, os gestores constroem uma narrativa sobre os benefícios, mirando o engajamento dos músicos, potenciais beneficiários desse processo, e depois do êxito com o título os artistas são ignorados como mostra o não pagamento dos direitos autorais.

Os direitos de autor são uma forma de proteção destes agentes no mercado cultural, sendo seu trabalho e difusão subordinados, com frequência, aos conglomerados midiáticos e outros agentes. Percebe-se que essa "modernização" não é para eles quando a Prefeitura não quita dívidas relativas ao recolhimento de direitos autorais (FALCÃo; SoARES FILHO, 2012).

A advogada especialista em direito autoral, Cristiane Olivieri diz:

Não obstante exista, ainda, uma visão romântica em relação ao artista, a qual o vincula a boêmia e a pobreza poéticas, é a falta de condições financeiras, que, por vezes, inviabiliza a continuidade da produção artística. Assim é essencial perceber, que a única remuneração do autor advém da venda da própria obra e de sua exploração econômica. O respeito ao direito autoral é importante, pois, além de poder garantir a sobrevivência do autor e da própria obra, pode traduzir-se em negócio rentável para os envolvidos e em divisas para o país (OLIVIERI, 2005, p. 162).

Tal cenário nos remete ao que Arantes (2000) chamou de "ironia objetiva" se referindo à nova gestão das cidades. A ironia objetiva trata justamente de converter “as melhores intenções no seu avesso, realizando, não por desvio, mas por fina- 
lidade interna" (ARANTES, 2000, p.11). Esse parece ser o espírito da criatividade alimentado pelos gestores, uma criatividade que está alheia aos criadores, como notaram Borges e Costa (2012), que é promovida por instituições que desconsideram as condições de trabalho dos artistas.

A Prefeitura Municipal de Salvador encomendou um diagnóstico do setor cultural promovido pela Fundação Gregório de Mattos e pesquisadores da área, que constatou que "os investimentos públicos direcionados à linguagem são pequenos e geralmente voltados às grandes produções, sem abarcar artistas com menor visibilidade. Não há políticas consistentes para alavancar o desenvolvimento cultural a partir da música" (SALVADOR, 2017, p. 75).

Analisando a política cultural do município se percebe que a debilidade não é exclusividade da música. Talvez por ser recente, não há um entendimento claro do papel e das potencialidades da cidade, sendo a sua política cultural pensada pelo governo estadual. Segundo Rubim:

As políticas culturais municipais têm sido, quando existentes, pífias. Este quadro assustador das políticas culturais municipais não deve ser imputado apenas à atual gestão, mas ele marca a história recente de Salvador. Como a prefeitura, durante a ditadura e no pós-ditadura, foi tratada pela corrente política que dominou a Bahia apenas como um apêndice do governo estadual, Salvador foi destituída de políticas públicas municipais em muitas áreas, inclusive na cultura (RuBim, 2014, p. 214).

A administração de Antônio Carlos Magalhães Neto, entre 2013 e 2020, passou a seguir o ritmo da política cultural nacional, criando algumas leis:

1) Lei $n^{\circ} 8.551 / 2014$ para instituir um Sistema Municipal de Cultura;

2) Lei $9.174 / 2016$ prevendo a participação do capital privado nas atividades culturais;

3) Decreto $\mathrm{n}^{\mathrm{o}} 30.230$ de 24 de setembro de 2018, criando o Conselho Municipal de Política Cultural - CMPC.

Certamente, a finalidade é a da adesão ao Sistema Nacional de Cultura - SNC, que prevê a implementação de uma gestão integrada da cultura, unindo todas as esferas governamentais em um sistema interligado. Responsabilidades e deveres, neste caso, são repartidos entre as diferentes instâncias (municípios, estados, distrito federal e União), em consonância com Emenda Constitucional $\mathrm{n}^{0}$ 71, de 
2012, que acrescenta o art. 216-A à Constituição Federal para instituir o Sistema Nacional de Cultura.

Quanto ao orçamento da Secretaria de Cultura e Turismo em 2019, foram destinados $\mathrm{R} \$ 287,6$ milhões de reais. Destaca-se que parte deste orçamento é disponibilizado para reformas e construções, a exemplo do centro de convenções, reestruturação das orlas das praias de Stela Maris, Flamengo e Ipitanga no âmbito do Programa do Desenvolvimento do Turismo - PRODETUR, por meio de empréstimo da Prefeitura junto ao Banco Interamericano de Desenvolvimento - BID, cujos objetivos são maximizar

As visitas à cidade, bem como a parcela desses gastos que beneficia à população local e, particularmente, a população afrodescendente, mediante o incentivo ao turismo cultural e de sol e praia, a melhoria da infraestrutura e o apoio institucional à gestão do turismo (SALVADOR, 2019).

O relatório ainda apontou que Salvador possui as seguintes fragilidades (SALVADOR, 2017):

1) Políticas culturais débeis no tocante à linguagem musical;

2) O patrocínio privado é baixo e há desconhecimento das leis de incentivo por parte do empresariado;

3) Investimentos focados apenas em eventos comerciais;

4) Ausência de agenda cultural no âmbito municipal;

5) Poucos espaços culturais nas periferias;

6) Falta de programas de formação de público;

7) Pouca participação dos artistas locais em eventos realizados pela prefeitura.

A Fundação Gregório de Mattos - FGM, responsável pelas ações de estímulo e fomento, destinou-se apenas $\mathrm{R} \$ 16.543 .000,00$ do montante geral, sendo apenas $\mathrm{R} \$ 10.630,00$ para o desenvolvimento de projetos, segundo a Lei de Diretrizes Orçamentarias - LDO de 2019. Muito embora tenha tomado todas essas decisões em prol da cultura, a administração municipal sequer tem uma secretaria exclusiva para a cultura em pleno ano de 2021, denotando incompreensão com a área em questão.

Constata-se que a administração municipal e a cidade não dispõem de políticas específicas para abarcar e distribuir os êxitos dessa conquista com os artistas locais. Entrei em contato com a Secretaria de Cultura e Turismo e com a Fundação 
Gregório de Mattos solicitando mais informações e documentações sobre a cidade da música, mas até a data desta redação não obtive resposta.

\section{EXPERIÊNCIAS DE ARTISTAS NA CIDADE DA MÚSICA}

Sabe-se que há 111.613 ocupados criativos e setores correlacionados na Bahia, sendo que $45 \%$ estão na capital baiana. São cerca de 50.230 profissionais, distribuídos entre as áreas que compõem o segmento criativo (Bahia, 2014). Já a pesquisa Salvador mais criativa remete a 43 mil ocupados nos setores culturais criativos (CANEdo; JHouri, 2015). Segundo o Mapa Musical da Bahia, realizado pela Fundação Cultural do Estado da Bahia (FuncEB), 58,06\% dos artistas do Estado não vivem exclusivamente da música e 65.32\% dos músicos do estado residem em Salvador (BAHIA, sem data). Não é de causar estranheza o desconhecimento de muitos artistas em relação a tal chancela? Pus-me a entender os porquês do desconhecimento, e, para tanto, contei com a ajuda, o depoimento e a experiência de dois artistas da cidade que sintetizam, em alguma medida, as informações obtidas com os demais entrevistados durante a pesquisa de doutorado, em 2018.

As experiências são sempre históricas, tecendo elos entre a subjetividade dos indivíduos e as estruturas sociais. Segundo Raymond Williams (1979), as experiências propiciam não só entender as forças políticas que lutam para se tornarem hegemônicas, mas também aquelas forças emergentes e diversificadoras. Um de meus interlocutores iluminou o caminho: Henrique, 53 anos, músico profissional, percussionista e professor.

Rapaz, já não me encanto com essas pompas de fora, eu sou velho, vi o Pelourinho, expulsaram meio mundo de gente, foi uma expectativa só, hoje a gente tá aqui apenas com prédios e fachadas embelezadas, mas sem emprego. No início parecia que realmente Salvador iria nos valorizar, mas não foi isso que aconteceu. O que tem aí é mais para os empreendedores mesmo, aquele que teve um dinheiro pra investir, dono de restaurante, pousada, etc. Os meninos pobres tão aí na droga, apanhando, "levando tiro", vendendo esses cafés pra cima e pra baixo. Meninas na prostituição! E outra, essa pauta é mais antiga, seja feita justiça, o Olodum aqui luta pra que haja o reconhecimento daqui há quantos anos! Rapaz, é desde o final de 1970. Percebe! Até a pauta é roubada da gente, virou essa coisa de embelezar os prédios e esqueceram das pessoas. Para você ter uma ideia do que estou falando nem segurança séria aqui tem, ninguém quer vir aqui a noite, quando vem é assustada. A política aqui errou e feio, aqui é para ser lugar ícone, o lugar do embelezamento, você entende? Um embelezamento para pagar os erros 
da história, porque no Pelourinho já se fez muitas coisas ruins, você é sociólogo (pesquisador) sabe dessas coisas, deve saber mais do que eu até.

Jefferson: Você está se referindo à escravidão, não é?

Henrique: Claro que sim! Esses embelezamentos enganam muitagente, é isso! É uma forma de apagar o passado, mas essas ideias novas são antigas no fundo, são novas as palavras, mas o jeito das coisas é mesmo a prisão da gente. Políticos não beneficiam a gente, independente de lado da política, porque existe uma coisa maior de intimidação do pobre na sociedade, que é o poder do dinheiro. Quem tem, tem, quem não tem resta o trabalho e reivindicar. Artista tem que dialogar com essa gente, porque recebe um cachê, faz um projeto ou outro, mas não deve se enganar com qualquer coisa. O conhecimento está aí pra a gente não deixar passar em branco essas ideias estranhas. Músico aqui não viu essa melhoria toda que prometeram, talvez se quem inventou isso tudo fosse músico e vivesse da música, da arte ou da cultura, as coisas estivessem, funcionassem melhor. É verdade, aqui vem mais turista, mas e daí?! Aqui não é zoológico, negão! $O$ povo vem pra cá com cada cabeça, tudo querendo ser bem tratado e não se importa em entender as coisas daqui, acho até errado como tratam a gente, a gente só serve pra servir. Com essa volta, eu quero dizer que não estou confiando nisso não. E desse que você me falou, cidade da música, aqui ninguém falou, ou seja, nem a gente sabe (HENRIQUE, 53 anos, 16/o9/2018, grifos colocados) ${ }^{11}$.

A incredulidade de Henrique na cidade criativa está lastreada nas contradições da gentrificação estabelecida no Centro Histórico de Salvador. O lugar passou a ser visitado graças à visibilidade mundial trazida pela Unesco, mas uma cidade, seus moradores e, particularmente, seus artistas necessitam de uma política cultural que propicie mais do que visitantes, que, mormente, têm uma relação superficial e hierarquizada com as pessoas locais (vistas frequentemente como serviçais) - "É verdade, aqui vem mais turista, mas e daí?! Aqui não é zoológico não! [...] Agente só serve para servir", conforme Henrique.

Com a experiência de Henrique se percebe que a cidade criativa expressa, mais uma vez, o conflito entre os perdedores e os vencedores da globalização. Com o raciocínio de Henrique é possível indagar: a que preço as elites políticas e empresariais continuarão a encarar esses processos internacionais como forma de desenvolvimento calcado no potencial histórico e/ou natural?

11 Entrevista ao longo do trabalho de campo realizado em 2018. 
Henrique entende a cidade da música como mera replicação de uma ideia já conhecida. Parece razoável sua visão, pois embora essas ideias sejam novas, elas são operadas em Salvador por velhos grupos políticos ou, como ele disse, "já não me encanto com essas pompas de fora", e ainda "essas ideias novas são antigas no fundo, são novas as palavras, mas o jeito das coisas é mesmo a prisão da gente”.

Justifico o entusiasmo de Henrique quanto à reurbanização do Pelourinho em meados de 1980 e a quebra de expectativa quanto à cidade da música com a seguinte hipótese: tanto o Brasil quanto a Bahia e, logicamente, Salvador, não conheciam uma política cultural à época, de modo que a política da Unesco parecia o que havia de mais relevante e inclusivo na área, afinal, parte do que existe hoje é uma estrutura administrativa criada ao longo da década de 1990, especialmente a partir de 2003.

O programa Cultura Viva, que existe desde 2004, exemplifica um processo de inclusão mais abrangente do que aqueles promovidos por essas políticas receitadas por organismos internacionais. Foi a forma que o governo encontrou "para lidar com tais desafios, o programa Cultura Viva busca impulsionar ações culturais já existentes em todo território nacional” (MEDEIRos; Lima, 2011, p. 218), mesmo assim houve e há ruídos:

Na discussão sobre a estratégia de implementação do programa, grande parte dos problemas de gestão pode ser atribuída à recente aproximação do Estado e da sociedade civil para a realização de políticas públicas, que traz certa incompatibilidade entre as linguagens de um e outro ator. Ainda que a estratégia seja fundamental para a democratização das políticas, há uma espécie de "despreparo" por parte do Estado para lidar com a diversidade dos grupos da sociedade civil, e desta para com a linguagem burocrática do Estado. Assim, o primeiro parece ter uma linguagem mais precisa e técnica, e a segunda geralmente trabalha com linguagens mais espontâneas e fluidas. Em razão disso, os procedimentos jurídico/burocráticos tornam-se complicadores na relação entre estado e sociedade civil, dificultando a execução dos convênios e se manifestando em especial no momento da prestação de contas (Medeiros; Lima, 2011, p.)

Mesmo com as reservas apresentadas pelas autoras, o Cultura Viva ganhou uma capilaridade pelo território, enfrentando a costumeira e dramática insularidade tanto da Lei Rouanet quanto das políticas da Unesco, calcadas em cidades, setores e linguagens artístico-culturais. As políticas da Unesco primam pelos empresários e secundarizam a população da cidade, estas aparecem apenas na 
fábula dos empregos e da renda, ou seja, é uma tecnologia administrativa produtora de mais desigualdade, embora envolta no discurso da salvaguarda da cultura, da arte e da natureza. O desconhecimento dos artistas mostra o encastelamento das decisões, algo que, claro, não é inaugurado por essa gestão, mas uma marca desse grupo político, segundo Dantas Neto (2006), a autocracia.

O Centro Histórico de Salvador e a própria ideia da cidade da música evidenciam a exclusão dos artistas. Até existe uma tendência no sentido de equacionar "desequilíbrios persistentes no fluxo de bens e serviços culturais" (DeLomaux, 2018), mas, com frequência, esse desequilíbrio é visto numa relação Norte/Sul global (EL BennaOUI, 2018). Problemas locais permanecem e são manejados politicamente, cito novamente a pesquisa encomendada pela prefeitura da cidade, que diz o seguinte sobre o Pelourinho:

O Pelourinho é um exemplo de região com um número significativo de espaços para shows, mas as estruturas deficitárias encarecem o custo da produção e inviabilizam projetos, além das questões de infraestrutura da cidade como transporte e segurança, que têm influenciado no esvaziamento dos espaços culturais e na redução do público (SALVADOR, 2017, p. 75).

Em pleno ano de 2017, no segundo aniversário da cidade da música, a gestão ainda não conseguiu dirimir problemas infraestruturais em um dos seus principais palcos. Não obstante, a Unesco e os órgãos locais esquecem de abordar as assimetrias e contradições na perspectiva local, a exemplo da concentração de recursos materiais e simbólicos, da falta de transparência, da inadimplência de agentes públicos e, até mesmo, deixa de pensar nas desigualdades quanto à raça, ao gênero, à sexualidade, à juventude, entre outros marcadores (DANTAS, 2018).

Jorge é outro interlocutor: ator e músico, 37 anos, a música e o teatro fazem parte de sua vida desde a adolescência. Jorge é natural de Salvador, ficou fora da cidade durante apenas três anos, quando morou no Rio de Janeiro.

Eles elegem um setor. Mas não precisa deixar os outros de fora. Artista é tudo igual, rapaz! Aqui e fora, todos sabem que a Bahia é lugar de boa música, qual a novidade dessa palhaçada? É realmente preciso que venha a ONU dizer que somos criativos, musicais ou dizer que a comida daqui é boa? Acho que eles deveriam ver a questão da paz, em vez de falar de arte, lá tem artista ou é a turma do terninho? Eles são a burocratividade! É um povo que se aventura sobre tudo que há nessa Terra. Não é necessário ser muito inteligente para sacar que 
essas novidades escondem por trás delas muitas coisas ruins para a gente que vive de arte. $O$ teatro é bem ruim de viver aqui, a música até dá, se você não liga muito para frequentes humilhações, o carnaval aqui é isso [...]criativo, eu acho que todos são. Mas é aquilo, nem tudo que é criativo é artístico a meu ver. Criativo vem de criar as coisas que não existem, coisas novas em ramos diferentes, uma sacola que tem uma característica diferente das demais. É isso, para mim, criativo não é necessariamente arte, criativo pode ser sobre alguma utilidade para alguma dona de casa (JoRGE, 19/09/2018, grifos colocados).

Jorge é descrente da ideia de que a cidade da música trará frutos para os artistas e salienta que não só a música deve ser celebrada, mas todas as linguagens artísticas, considerando os artistas igualmente importantes. $\mathrm{O}$ artista mostrou certo incômodo com a ideia de cidade criativa e num tom jocoso fez menção à "turma do terninho", forjando, inclusive, o vocábulo "burocratividade", um conceito do universo da prática artística que questiona a autoridade desse grupo social na reformulação das políticas culturais, expondo ainda os tentáculos da racionalização.

Em tese, a burocracia estatal serve aos ditames da política, aos anseios do bem geral. Contudo, a revisão bibliográfica e as narrativas de meus interlocutores apontam para o hiato entre a gestão e a concepção da política cultural, equívocos e fragilidades destas políticas no tocante à promoção da cultura como direito, seja na produção, seja no acesso aos bens artístico-culturais (BоTELHo, 2007; CALABRE, 2007; RuBim, 2007). A linguagem burocrática, na prática, tem significado para os artistas certa asfixia. A via crucis do artista brasileiro no contexto destas políticas culturais neoliberais, reiteradas à exaustão. Repete-se, por obra das estruturas de poder, de acordo com Weber (1999), o poder consiste na probabilidade de encontrar obediência a uma ordem, ou seja, trata-se da probabilidade de estabelecimento de uma dominação. As leis de incentivo compõem a feição atual da dominação no setor artístico, onde, por meio de dispositivos legais, corporações impõem o seu ritmo aos artistas e ao público envolvidos na vida cultural das cidades.

A criatividade tão festejada e incentivada pelos organismos multilaterais suprime o trabalho por trás da obra, apagando a materialidade de sua produção, alienando assim o caráter material e social da atividade artística que é, a um só tempo, material e imaginativa. Tanto a literatura especializada estrangeira (ConDE, 2009; Connor; Gill; TAYlor, 2015; DinARdi, 2019; Haunschild, 2003; Hesmondhalgh; BAKER, 2008; MENGER, 2005; OliveIra, 2014), quanto a nacional (REIS, 2012; SEGNINI, 2016, 2018) apontam para a precarização do trabalho artístico, provocada por 
múltiplas e recentes mudanças no capitalismo, tanto em sua dimensão de assalariamento, quanto na informalidade.

Em Salvador, o trabalho artístico é realizado em uma economia de colaboração e pouquíssimos artistas têm contratos estáveis de trabalho, quase um privilégio. Na capital baiana, os artistas são majoritariamente microempreendedores individuais ${ }^{12}$, que intercambiam diversos serviços.

Também é imperioso fomentar a institucionalização de artistas, grupos culturais, de iniciativas de inovação cultural e de redes. Portanto, é importante criar os meios para que os atores criativos se sintam preparados para empregar o talento pessoal e as potencialidades do entorno para empreender na geração de bens, produtos e serviços de valor simbólico. Deste modo, poderão inovar, reinventar e recriar a economia criativa de Salvador a partir do contexto local (CANEDO, 2017, p. 270).

Daniele Canedo ajuda a pensar a complexidade do trabalho artístico em Salvador quando alude à falta de recursos para o setor artístico-cultural e à necessidade de permanente articulação entre os setores da gestão pública, os artistas e a população. Demonstra ainda a carência de cursos e capacitações dedicadas aos artistas da cidade como estratégia para o engajamento dos indivíduos, iniciativas essenciais para conjugar a expertise artística e a burocrática (o que promoveria trabalho e renda, uma vez que as práticas artísticas em Salvador são dependentes do poder público).

Na generalidade, os artistas entendem que não podem esperar por governos, pois, independente do partido político, ambos os grupos citados tratam de aplicar um conjunto similar de medidas, "um convívio promíscuo da cultura do dissenso com os donos do poder e do dinheiro" (ARANTes, 2000, p. 12). Destarte, os artistas expressam mais pragmatismo do que pessimismo ao ensejarem uma forma de resistir por dentro da estrutura, dispostos a negociar com quem está inclinado a negociar, aceitando a linguagem proposta pelo outro lado. Os artistas participam da dinâmica do poder requerendo uma parte dos recursos materiais e simbólicos que o jogo envolve.

12 Esse discurso serve como forma de harmonizar a relação capital/trabalho ao passo que constrói uma subjetividade preparada para uma vida concorrencial em uma sociedade sem direitos sociais (DARDOT; LAVAL, 2016). 


\section{CONSIDERAÇÕES FINAIS}

A interlocução durante a pesquisa de campo apontou para algumas características do processo de implementação da cidade da música em Salvador. De um lado, há uma narrativa sobre a colheita de louros, um discurso que vende a cidade feita pelos gestores, ao passo que, do outro lado, os artistas evidenciam o fardo da criatividade.

A pesquisa informou dificuldades básicas na operacionalização da cidade criativa, posto que falta atenção aos direitos dos artistas, baixa participação e controle dos artistas, pouca transparência, baixo investimento e manutenção precária de espaços de socialização artística, portanto, há uma discrepância entre a propaganda e a realidade. Informou ainda que os trabalhadores das artes e da cultura vivenciam a desproteção social, emendando diversas atividades laborais para alcançar um patamar decente de renda, enfrentando todo e qualquer tipo de trabalho.

Por fim, ainda é cedo para batermos o martelo quanto aos resultados da cidade da música, no entanto, a inadimplência para com os direitos autorais de músicos e o baixo desenvolvimento cultural são contradições basilares que põem em xeque a cidade criativa tal como empreendida na capital baiana hoje.

\section{REFERÊNCIAS BIBLIOGRÁFICAS}

Alves, M.A. O trabalho de técnicos de palco no contexto de um teatro público: décadas de 1950 a 2000. Campinas: Revista Proa: Revista de antropologia e arte. IFCHUNICAMP, $n^{0}$ 01, vol. 01, 2009.Disponível em: http://www.ifch.unicamp.br/proa. Acesso em: 10 nov. 2018.

Aragão, Verlane; Bolaño, César; Lopes, Ruy S. Uma economia política da cultura e da criatividade. In: Claudia Leitão; Ana Flavia Machado. (Org.).Por uma Brasil Criativo: significados, desafios e perspectivas da economia criativa brasileira. 1ed. Belo Horizonte: Código Editora, 2016, v. 1, p. 9-23.

ARANTES, O. Uma estratégia fatal: a cultura nas novas gestões urbanas. In: A cidade do pensamento único: desmanchando consensos. (Orgs). Arantes, O., Vainer, C. e MARICATO, E. Petrópolis: Editora Vozes, 2000.

BAHIA. Governo do Estado da Bahia. Infocultura: ocupação e trabalho na economia criativa do estado da Bahia - 2010. V.1, n.7, (dez. 2014). Salvador: Secretaria de Cultura do Estado da Bahia, 2014.

Bahia. Governo do Estado da Bahia. Mapa musical da Bahia.Fundação Cultural do Estado da Bahia. Disponível em: http://mapamusical.ba.gov.br/o-projeto/. Sem data. Acessoem: 23 set. 2019. 
Bolaño, C. R. S.. "Trabalho Intelectual, Comunicação e Capitalismo. A reconfiguração do fator subjetivo na atual reestruturação produtiva”. Revista da Sociedade Brasileira de Economia Política, Rio de Janeiro, v. oo, n.11, p. 53-78, 2002.

BORGES, V; Costa, P.(orgs.) Criatividade e Instituições: novos desafios à vida dos artistas e dos profissionais da cultura. Lisboa: Imprensa de Ciências Sociais, 2012.

BотеLно, Isaura. A política cultural \&o plano das idéias. In: Políticas culturais no Brasil / (orgs.) Barbalho, A. e Rubim.A.A.C -Salvador: edufba, 2007.

BRASIL. Lei Complementar $\mathrm{n}^{0} 128$, de 19 de dezembro de 2008. Altera a Lei Complementar no 123, de 14 de dezembro de 2006, altera as Leis nos 8.212, de 24 de julho de 1991, 8.213, de 24 de julho de 1991, 10.406, de 10 de janeiro de 2002 - Código Civil, 8.029, de 12 de abril de 1990, e dá outras providências, 2008. Disponível em: http://www. planalto.gov.br/ccivil_03/leis/lcp/lcp128.htm. Acesso em: 26 fev. 2021.

BRASIL. Emenda constitucional No 71, DE 2012. Acrescenta o art. 216-A à Constituição Federal para instituir o Sistema Nacional de Cultura. Disponível em: https://www2. camara.leg.br/legin/fed/emecon/2012/emendaconstitucional-71-29-novembro-2012774688-publicacaooriginal-138236-pl.html.Acessoem: 23 set. 2019. 23/o9/2019.

Brasil. LEI N. 14.017, de 29 de junho de 2020. Dispõe sobre ações emergenciais destinadas ao setor cultural a serem adotadas durante o estado de calamidade pública reconhecido pelo Decreto Legislativo n. 6, de 20 de março de 2020. Diário oficial da União: seção 1, Brasília, DF, n. 123, p. 1, 30 jun. 2020. Disponível em: https://www. in.gov.br/en/web/dou/-/lei-n-14.o17-de-29-de-junho-de-2020-264166628. Acesso em: 26 fev. 2021.

CAlabre, Lia. Políticas culturais no Brasil: balanço \&perspectivas. In: Políticas culturais no Brasil / (orgs.) BARbalho, A. e Rubim. A.A.C -Salvador: edufba, 2007.

CAnedo, Daniela; Khouri, Ricardo. Salvador Mais Criativa: atores e Redes Culturais e Criativas de Salvador. In: Prefeitura Municipal de Salvador. Fundação Mário Leal Ferreira (Coord.). Plano Salvador 500 anos abrangendo o Plano Diretor de Desenvolvimento Urbano -PDDU e a Lei de Ordenamento do Uso e Ocupação do Solo - LOUOS. Salvador, 2015.

CANEDo, D.P. Trabalho e renda na economia criativa de Salvador.In:Os trabalhadores $d a$ cultura no Brasil: criação, práticas e reconhecimento / Alexandre Barbalho, Elder Patrick Maia Alves, Mariella Pitombo Vieira (organizadores). - Salvador: EDUFBA, 2017.

Cerqueira, A. Paradoxos da atividade artística na narrativa de músicos denominados independentes. Tese de doutorado. Instituto de Filosofia e Ciências Humanas. Universidade Estadual de Campinas. Campinas, São Paulo, 2017. 
CondE, Idalina. Artists as vulnerable workers. CI20o9ESe-working papers, $\mathrm{n}^{\circ}$ 71/2009, Lisboa, 2009.

Connor, B; GILL, R; TAYLOR, S. Gender and creative labour. The Sociological Review. The Editorial Board of the Sociological Review, 63: S1, 2015, p. 1-22.

DANTAS, Jefferson. Mise-en-scène da precarização: estudo sobre o trabalho de jovens atores em Salvador. In: Juventudes e movimentos/Frank Marcon; Danielle Parfentieff de Noronha (organizadores). Aracaju: Criação, 2018.

Dantas Neto, P. F. Tradição, autocracia e carisma- a política de Antônio Carlos Magalhães na modernização da Bahia (1954-1974). Belo Horizonte: Ed. UFMG, 2006.

Dardot, Pierre; Laval, Christian. A nova razão do mundo. Ensaio sobre a sociedade neoliberal. São Paulo: Boitempo, 2016.

Deloumeaux, L. Desequilíbrios persistentes no fluxo de bens e serviços culturais. In: Re|pensar as políticas culturais: criatividade para o desenvolvimento 2018; relatório global da Convenção de 2005. - Brasília: UNESCO, 2018.

De Marchi, Leonardo. Construindo o conceito de economia criativa no Brasil: Política cultural no contexto neodesenvolvimentista brasileiro, Intercom - Sociedade Brasileira de Estudos Interdisciplinares da Comunicação XXXV Congresso Brasileiro de Ciências da Comunicação - Fortaleza, 2012.

Dinardi, Cecilia. Creativity, informality and cultural work in Rio de Janeiro's favelas. International Journal of Cultural Studies, Sage Journals, 2019, p.1-16.

EHrEnBERG, Alain. $O$ culto da performance. Da aventura empreendedora à depressão nervosa/ Alain Ehrenberg. Organização e tradução Pedro F. Bendassoli. - Aparecida, Sp: Ideias \&Letras, 2010.

El Bennaoui, Sobreviver aos paradoxos da mobilidade. In: Re|pensar as políticas culturais: criatividade para o desenvolvimento 2018; relatório global da Convenção de 2005. Brasília: UNESCO, 2018.

Falcão, Caio Valério Gondim Reginaldo, Soares Filho, Sidney S. Direito autoral e ecad: análise jurisprudencial do papel do escritório central de arrecadação e distribuição na cobrança judicial pela execução pública de obras musicais e congêneres. RJurFA7, Fortaleza, v. IX, n. 1, p. 53-64, abr. 2012.

Ferreira, V.M.S. A rede de cidades criativas da Unesco: uma perspectiva das cidades brasileiras. Dissertação de mestrado. Universidade Federal de Goiás, Faculdade de Artes visuais, Programa de Pós-graduação em Arquitetura- projeto e cidade, Goiânia, 164 pgs, 2017.

FIRJAN. Mapeamento da indústria criativa no Brasil. Federação das Indústrias do Estado do Rio de Janeiro Sistema.FIRJAN. Rio de janeiro, 2016.

HARTLEy, J. Creative Industries. London: Blackwell, 2005 
Harvey, David. Condição Pós-Moderna: uma pesquisa sobre as origens da mudança cultural. 6 ed. São Paulo: Loyola, 1996.

HaRvey, David. A arte de lucrar: globalização, monopólio e exploração da cultura. In: Moraes, D. (org.). Por uma outra comunicação: Mídia, mundialização cultural e poder. Rio de Janeiro: Record, 2003.

Harvey, David. O novo Imperialismo. São Paulo: Edições Loyola, 2005.

HaUnsCHILD, Alex. Managing employment relatiosnship in flexible labour markets: the case osgerman repertory theatres.Human Relations. Volume 56(8), 2003.

Hesmondhalgh, D. \& Baker, S. Creative Work and Emotional Labour in the Television Industry. Theory, Culture \& Society (SAGE, Los Angeles, London, New Delhi, and Singapore), Vol. 25(7-8), 2008.

Howkins, J. The Creative Economy: How People Make Money From Ideas. London: Allen Lane, 2001.

Huws, Ursula. Mundo material: o mito da economia imaterial. Mediações, Londrina, v. 16, n.1, p. 24-54, Jan./Jun. 2011.

IBGE. Instituto Brasileiro de Geografia e Estatística. Pesquisa Nacional por Amostra de Domicílios. PNAD. $4^{\circ}$ trimestre, 2019. Disponível em:https://www.ibge.gov.br/ estatisticas/sociais/trabalho/9173-pesquisa-nacional-por-amostra-de-domicilioscontinua-trimestral.html?edicao $=26895 \& \mathrm{t}=$ destaques $>$. Acesso em: 26 fev. 2021 .

IsaR, Y. Visão Global: Das Inquietações Conceituais a uma Agenda de Pesquisas. In: REIS, A.C.F. Economia criativa: como estratégia de desenvolvimento: uma visão dos países em desenvolvimento / organização Ana Carla Fonseca Reis. - São Paulo: Itaú Cultural, 2008.

Medeiros, A.K; Lima, L.P.B. Descentralização e articulação enquanto estratégia de expansão de políticas públicas: estudo de caso do programa cultura viva. In: Cultura viva: as práticas de pontos e pontões / Ipea, Coordenação de Cultura. Brasília: Ipea, 2011.

Menger, Pierre-Michel. Retrato do artista enquanto trabalhador:metamorfoses do capitalismo. Lisboa: Editora Roma, 2005.

Neto, A. C. M. Unesco reconhece oficialmente Salvador como 'Cidade da Música'. G1. Rede Bahia. Entrevista. Salvador, 2016. Disponível em: http://g1.globo.com/bahia/ noticia/2016/o6/unesco-reconhece-oficialmente-salvador-como-cidade-da-musica. html. Acesso em: 24 fev. 2021.

OBEC/BA.Observatório de Economia Criativa da Bahia, Boletim 3, 08/05/2020, 2020. Disponível em:https://ufrb.edu.br/proext/economiacriativa-covid19/.Acesso em: 26 fev. 2021.

Olivera, R.G. Multiactividad e intermitenciaenelempleo artístico. El caso de los músicos de conciertoen México. Universidad Nacional Autónoma de México-Instituto de 
InvestigacionesSociales. Ciudad de Mexico. Revista Mexicana de Sociología, 76, núm. 1, enero-marzo, 2014.

OLIviERI, Cristiane. O direito autoral e a produção cultural. In: Organização e Produção da cultura. (orgs) Rubim, Linda e Barbalho, Alexandre. Salvador. Edfuba. Facom/ Cult, 2005. Pp.161-169.

Pereira, Luiz Carlos Bresser.A Reforma do estado dos anos 9o: lógica e mecanismos de controle. Brasília: Ministério da Administração Federal e Reforma do Estado, 1997.

Reis, A.C.F. Cidades Criativas: análise de um conceito em formação e da pertinência de sua aplicação à cidade de São Paulo.Tese de Doutorado. Universidade de São Paulo. Faculdade de Arquitetura e Urbanismo. Planejamento Urbano e Regional, São Paulo, 2011.

Rubim, A. A. C.; Rubim, Iuri e Vieira, Mariella Pitombo. Políticas e redes de intercâmbio e cooperação em cultura no âmbito ibero-americano. In: CONVÊNIO ANDRÉS BELLO. Siete cátedras para laintegración. Bogotá, Convênio Andrés Bello, 2005, p.129-170.

Rubim. A.A.C.Políticas culturais no Brasil: tristes tradições, enormes desafios. In: Políticas culturais noBrasil / (orgs.) BarbalHo, A. e Rubim. A.A.C -Salvador: edufba, 2007.

Rubim, Antônio Albino Canelas. Políticas culturais na Bahia contemporânea / Antônio Albino Canelas Rubim; edição e preparação de texto, Iuri Oliveira Rubim. - Salvador: EDUFBA, 2014.

ReIs, Cacilda Ferreira. Sonhos, incertezas e realizações: as trajetórias de músicos e dançarinos afro-brasileiros no Brasil e na França. 2012. Tese (Doutorado em Ciências Sociais) - Universidade Estadual de Campinas, Campinas, 2012.

SAlvador. Prefeitura Municipal de Salvador. Diagnóstico do desenvolvimento cultural de Salvador, Secretaria Municipal de Cultura e Turismo. Fundação Gregório de Mattos, Salvador, 2017.

SAlVADOR. Prefeitura Municipal de Salvador. Lei de diretrizes orçamentárias,Casa Civil, 2019. Disponível em: http://casacivil.salvador.ba.gov.br/index.php/menu-orcamento/ lei-de-diretrizes-orcamentarias-ldo/2019. Acesso em: 26 fev. 2021.

SAlVADOR. Prefeitura Municipal de Salvador. O Programa de Desenvolvimento do Turismo na cidade de Salvador (PRODETUR Salvador). Secretaria de Culltura e Turismo. Salvador, 2019.Disponível em: http://www.prodeturssa.salvador.ba.gov.br/index. php. Acesso em: 23 set. 2019.

Santos, J. D. Para além do espetáculo: o trabalho de atores de teatro em Salvador. Tese de doutorado. Instituto de Filosofia e Ciências Humanas. Universidade Estadual de Campinas, Campinas, São Paulo, 2020. 
SEGNinI, L.R.P. Música, dança e artes visuais: especificidades do trabalho artístico em discussão. In: Trabalho artístico e técnico na indústria cultural[recurso eletrônico] / organização Liliana R.P. Segnini, Maria Noel Bulloni; tradução Marisa Shirasuna; textos Maria Aparecida Alves et. al. - São Paulo: Itaú Cultural, 2016.

SEGnini, L.R.P. Trabalho, imigração e relações de gênero no contexto da mundialização: músicos do Leste europeu no Brasil. Revista latinoamericana de estudiosdeltrabajo, v. 23, p.221-250, 2018. Disponível em: <http://alast.info/relet_ojs/index.php/relet/ article/view/336>. Acesso em: 31 jul. 2019.

SELDin, Claudia.Da capital de cultura à cidade criativa: resistências a paradigmas urbanos sob a inspiração de Berlim.Tese (Doutorado em Urbanismo) - Programa de Pós-Graduação em Urbanismo. Faculdade de Arquitetura e Urbanismo. Rio de Janeiro: UFRJ/FAU, 2015.

Throsby, David. Economics and culture.Cambridge: Cambridge UniversityPress, 2001.

UNESCO. Organização das Nações Unidas para a Educação, a Ciência e a Cultura.

International flows of selected cultural goods and services, 1994-2003: defining and capturing the flows of global cultural trade.UNESCO Institute for Statistics, Montreal, 2005.

VilhenA, D.F. Produção teatral: da prática à teoria. A sistematização de uma disciplina.V ENECULT- Encontro de Estudos Multidisciplinares em Cultura Faculdade de Comunicação/UFBa, Salvador, 2009.

WEBER, Max. Economia e sociedade: fundamentos da sociologia compreensiva. Vol.2 tradução de Regis Barbosa e Karen Elsabe Barbosa; Revisão técnica de Gabriel Cohn Brasília, DF: Editora Universidade de Brasília: São Paulo: Imprensa Oficial do Estado de São Paulo, 1999.

Williams, Raymond. Marxismo e Literatura.Rio de Janeiro: Zahar, 1979.

Yúdice, George, A Conveniência da cultura: usos da cultura na era global. Belo Horizonte: UFMG, 2006. 